on the effect of heat treatment on chilled cast-iron and on the forgeability of metals. The Division of Biochemistry has been concerned with the development of a new system of combination vegetable tannage for sale and transmission belting leather. A microscopic method for the early diagnosis of bovine mastitis has been worked out by the Division of Pathology and Bacteriology, while other work of the Foundation has been concerned with the deodorization and partial hydrogenation of cod liver oil without destroying the vitamin content, with the incidence of diseases of apples and related problems, and with a process for transferring pigments used in the paint industry from aqueous pastes to the oil phase.

\section{Desiccation in Africa}

A SUPPLEMENT to the Journal of the Royal African Society of January entitled "The Man-made Desert in Africa : Erosion and Drought" by Prof. E. P. Stebbing offers yet another warning that in many parts of the world drifting sand and eroding soil are beginning seriously to clog the wheels of administrative machinery. Erosion is a matter in which Africen Governments interfere unwillingly, for effective control often means uprooting social, agricultural and religious customs upon which tribal life, which British Governments strive to preserve, is based. In this paper, Stebbing regards erosion primarily from the point of view of its effect on water supplies, and believes that with increasing orosion, a falling water-table and decreasing water supplies, the character of the rainfall deteriorates, wet years becoming less, and droughts more frequent, and of longer duration. When deterioration has reached what Stebbing terms the "intermittent rainfall stage", where continuous agriculture is scarcely feasible, man has his last chance to change his methods and prevent the final encroachment of the desert. Much of Africa seems to have entered upon this critical stage of deterioration, and some parts have passed it irrevocably. Stebbing emphasizes that now "it is for the Administration to act". The immediate needs for Africa's conservation are more money and more officers trained to the work. Given. these, administrations might put into operation soil conservation programmes which, if carried out, would turn the scales, at or before the intermittent rainfall stage, against the desert's encroachment. The trouble is that we cannot tell, until we have tried them out, whether plans for soil conservation are compatible with plans for the harmonious social development of whites and blacks.

\section{Grass Seed Production}

THREE new bulletins have been issued in the Herbage Publication Series by the Imperial Bureau of Plant Genetics, Aberystwyth. Bulletin 19, "Production of Grass Seed" (price 5s.), is edited by R. O. Whyte and consists of an international exchange of opinions and experiences on the technique of producing seed of graminaceous herbage and forage plants. The countries represented are Scotland, Northern Ireland, New Zealand, the United States,
Germany and Sweden, the names and addresses of the contributors being supplied in each case. Bulletin 20, "Insect and other Pests injurious to the Pro. duction of Seed in Herbage and Forage Crops" (price 2s. 6d.), has been prepared by H. F. Barnes. This paper is essentially a summary of the available information concerning some of these pests, but although growers should find this most useful, they are nevertheless advised to consult the advisory entomologist in their particular area as to the best method for safeguarding their crops, as it is impossible to secure really satisfactory results without due attention to local conditions. Bulletin 21, "The Influence of Climatic Conditions on Type Composition", by Nils Sylvén (price 1s.), gives an account of experiments in Sweden on the changes induced in herbage plants grown for seed outside their proper growing districts. It is evident that there is consider. able danger of loss of valuable characters if this process is continued. For satisfactory results, seed must be obtained direct from the breeding station or its vicinity, and care taken to keep seed from the original source scrupulously apart from that grown in a different locality, or much of the value of the selection work will be lost.

\section{Education in the Indian Villages}

A Paper by Capt. J. W. Petavel before the Economics Society of Osmania University on September 24 last year emphasizes the value of educative employment in the economic system of the Indian village, and particularly that of the educational colony in Indian rural education. One of the greatest possibilities to be explored, however, is that of the use of educational colonies for town children and adolescents, and these should be for the benefit of poor middle-class people as well as for the working classes and should include secondary as well as primary education. Stress is laid in this system on productive work, and the scheme of factory colonies outlined is also advocated as a contribution to improved world relations. Both in the rural and in the factory colonies one of the primary needs is the co-operation of scientific men and other professional workers in leadership and on a part-time basis in teaching and other capacities. Moreover, the colony organization offers one of the best opportunities of dealing with India's root problem of increasing the productivity of the land to yield more food for her growing population. The establishment of a standing committee for unemployment and poverty problems, to plan and assist research in the directions indicated by the success of the Swiss labour colony of Witzwil, is also urged.

\section{Report of the University of Leeds}

THE University of Leeds report for 1936-37 records as the outstanding event of the year a gift of $£ 200,000$ by Mr. Frank Parkinson. It is significant that the report gives prominence to Mr. Parkinson's expressed belief "that the university can render the highest service to the community by keeping the realities of life and the need of breadth of vision in 
human affairs before its students" and refers to an expression of the same belief by Lord Nuffield. Among other endowments were an anonymous gift of $£ 20,000$ and a legacy of $£ 25,000$ for founding a chair of psychology. The subject of employment of graduates is dealt with at greater length than is usual in these annual reports. In the technological departments, no difficulty was found in obtaining employment immediately after, and even before, graduation, To meet the situation created by the time-lag between graduation and employment in the teaching profession the Appointments Board exerted itself to find temporary summer employments. The usefulness of this Board is said to have greatly increased during the last few years, the number of vacant appointments notified to it having risen from 380 in 1932 to 3,500 in 1937. Appreciative reference is made to the report on employment of graduates published by the National Union of Students. Schemes for medical examination of students at their own option and for physical instruction were under consideration during the year and are now in process of realization.

\section{Quantitative Economics}

IN a paper on econometric researches, appearing in the series of publications dealing with economic problems edited by Dr, R. Gilrat (No. 412; Hermann and Cie., 6 Rue de la Sorbonne, 6, Paris, 1936), Prof. R. Ray deals with the demand for goods for direct consumption. Results obtained in this question of demand, whether by experimental methods or by the application of statistical methods to observations, afford a strong presumption in favour of the quantitative investigation of economic phenomena. Prof. Ray discusses the theories of Cournot, Dupint and Marshall, who considered demands as the function of a single variable, as well as the theories of Walras and the mathematical school. His own investigations on products for direct consumption suggest that for certain products or services, coefficients of elasticity can be used to characterize the demand. In considering the elasticity of demand, it is essential to analyse the part which the law of substitution plays, and accordingly it is desirable to limit the investigations to products which lend themselves less readily than others to substitution, or to investigate a group of products which are readily substituted one for another in meeting the same need. The method of multiple correlation offers interesting possibilities, and Prof. Ray concludes that the demand for goods or services investigated so far is nearly always inelastic.

\section{Effects of Dry Rot in Ships}

THE presidential address of Dr. John Ramsbottom to the Essex Field Club dealt with dry rot in ships. Its text appears in the Essex Naturalist (25, 231; 1937), and provides an interesting account of the struggle of naval builders with wood-rotting fungi. A historical survey from the sixteenth century onwards traces the use of various kinds and qualities of timber, and shows how prone they were to rotting within the vessel, and above the water-line. The diarist Pepys made some contributions towards an understanding of the problem, but it was largely the work of James Sowerby, the author of "English Fungi", which first directed attention to the real cause. He figured twenty-three species of "Fungi found in the Dockyards and. Ships of Great Britain from Deptford to Plymouth 1812". Merulius lachrys mans was included in the list, and there can be little doubt that it was one of the chief agents of decay. Many substances were used to impregnate timber in an effort to control the rot; but it was not until the appearance of ironclad ships that dry rot ceased to trouble the Royal Navy.

\section{The Rabbit Problem}

IN certain localities, as is well known, the prevalence of rabbits has become of some importance in horticulture, agriculture and forestry. In order to deal with this nuisance effectively and humanely, the University of London Animal Welfare Society (ULAWS) has published a pamphlet, entitled "Instructions for Dealing with Rabbits", compiled by Capt. C. W. Hume, in which the chief methods of rabbit destruction are fully described. In addition, a list of some relatively rabbit-proof plants and details of rabbit-proof fencing are given. Sir Frederick Hobday, in a foreword, commends the pamphlet, a copy of which will be sent free on receipt of a stamped envelope measuring 6 in. by 9 in. by ULAWS, 42 Torrington Square, London, W.C.1.

\section{Cambridge Dissertations for Degrees}

A BOok of "Abstracts of Dissertations approved for the Ph.D., M.Sc. and M.Litt. Degrees in the University of Cambridge" during the academic year 1936-37 has been issued (Published by Authority : The University Press, Cambridge, 1937.) Each summary has been approved by the examiners or by the student's supervisor, and gives a good idea of the matter of a dissertation. Copies of the dissertations are deposited in the University Library (Ph.D. degrees) or in the University Registry (M.Sc. and M.Litt. degrees).

\section{Reference Standards Laboratory}

AFTER a delay of many years, the establishment of a laboratory for the maintenance in Australia of standards of length, mass, electrical units, etc., has been approved by the Commonwealth Government. It will probably be placed at Canberra, the estimated cost of the building being $£ 80,000$. The administration will be in the hands of the Council for Scientific and Industrial Research, which will maintain intimate contact with the National Physical Laboratory at Teddington in general accordance with a plan drawn up some ten years ago.

\section{National Academy of the Lincei}

A supplementary number of the Atti della Reale Accademia Nazionale dei Lincei (1937) contains an account of the formal annual meeting held in Rome on June 6, 1937, in the presence of H.M. the King of Italy, to whom tribute was also paid for the first 